\title{
An Early Collaborative Intervention Focusing on Parent-Infant Interaction in the Neonatal Period. A Descriptive Study of the Developmental Framework
}

\author{
Charlotte Sahlén Helmer ${ }^{1, *(\mathbb{D})}$, Ulrika Birberg Thornberg ${ }^{2}$ and Evalotte Mörelius ${ }^{1,3} \mathbb{D}^{\mathbb{D}}$ \\ 1 Division of Nursing Sciences and Reproductive Health, Department of Health, Medicine and Caring Sciences, \\ Linköping University, SE-581 83 Linköping, Sweden; e.morelius@ecu.edu.au \\ 2 Department of Behavioural Science and Learning, Linköping University, SE-581 83 Linköping, Sweden; \\ ulrika.birberg.thornberg@liu.se \\ 3 School of Nursing and Midwifery, Edith Cowan University, Joondalup, WA 6027, Australia \\ * Correspondence: charlotte.sahlen.helmer@liu.se
}

\section{check for}

updates

Citation: Helmer, C.S.; Thornberg, U.B.; Mörelius, E. An Early Collaborative Intervention Focusing on Parent-Infant Interaction in the Neonatal Period. A Descriptive Study of the Developmental Framework. Int. J. Environ. Res. Public Health 2021, 18, 6656. https://doi.org/10.3390/ ijerph18126656

Academic Editors: Rachael Sharman and Michael Nagel

Received: 20 May 2021

Accepted: 17 June 2021

Published: 21 June 2021

Publisher's Note: MDPI stays neutral with regard to jurisdictional claims in published maps and institutional affiliations.

Copyright: (c) 2021 by the authors. Licensee MDPI, Basel, Switzerland. This article is an open access article distributed under the terms and conditions of the Creative Commons Attribution (CC BY) license (https:// creativecommons.org/licenses/by/ $4.0 /)$.

\begin{abstract}
Moderate to late preterm infants are at risk of developing problems later in life. To support attachment and infants' development, high quality parent-infant interaction is important. Parentinfant interaction is known to improve through intervention programs but since no such intervention program is addressed directly to moderate to late preterm infants, a tailor-made intervention was developed. The aim was to describe the rationale, development, framework and practical provision of a new early collaborative intervention program. This study has a descriptive design and the intervention is described using the Template for Intervention Description and Replication. During an intervention-session, the preterm infant's cues are made visible to the parents as they perform an everyday care-taking procedure. Instant feedback is delivered to give the parents the opportunity to notice, interpret and respond to cues immediately. The infant's response to the parent's action is discussed in a dialogue to instantly guide parents' awareness of the preterm infant's subtle cues. This study describes a new early collaborative intervention, developed to support interaction between parents and their moderate to late preterm infants starting in the neonatal intensive care unit. Clinical studies evaluating parental experiences as well as the effects of the early intervention are ongoing, ClinicalTrials.gov NCT02034617.
\end{abstract}

Keywords: behavior; caregivers; descriptive design; early intervention; family health; infant health; infant premature; intensive care neonatal; neonatal nursing; parents

\section{Introduction}

Parent-infant relations affect infant development [1]. Ainsworth described the need for the parent to be sensitive towards the infant's cues and to read, interpret and respond to the cues prompt and accurately, in order to develop a well-functioning parent-infant interaction [2]. Parent-infant interaction is an act where the parent and the infant modify their behaviors depending on the feedback provided by one other [3]. A sensitive and responsive interaction between parents and their infants facilitate a secure attachment $[4,5]$ and improve infant cognitive development [6].

The importance of early identification of risks in the parent-infant relationship, and a need to start supporting parents in the neonatal intensive care unit has recently been highlighted [7]. In neonatal care parent-infant relations are more vulnerable due to several factors which affect interaction patterns in families negatively. The cues of preterm infants are more subtle due to their immature neurological system [8], and thus more difficult to detect and respond to. Prolonged hospitalization, separation, parental distress, bonding difficulties and stress are other factors which hinder interaction [9-11].

Moderate to late preterm infants, are at a great risk of delays in physical and cognitive development [12-15]. The majority of the approximately 15 million infants born 
preterm [16] are born moderate or late preterm, between gestational week 32 and 37 [17,18], due to various reasons this group is constantly growing $[19,20]$.

Intervention programs starting at the neonatal intensive care unit have previously shown a positive effect on infant development [21-23] and parent-infant relations [24,25]. Brazelton developed The Neonatal Behavioral Assessment Scale (NBAS), designed to explain the infant's response to the environment and the infant's communicative and interactive behavior [3]. This assessment scale has inspired several interventions aiming to improve parent-infant interaction and has been used as an intervention in itself. However, a recent review found low evidence in the effect of NBAS as an intervention to improve parent-infant interaction [26]. Nevertheless, the way Brazelton described infant behavior and social competence, is valued and of great importance for our understanding of parentinfant interaction.

To our knowledge, few early intervention programs have aimed to support parentinfant interaction for moderate to late preterm infants. One exception is a study by Ravn, who used the Mother Infant Transaction Program [27]. However, this program is extensive [28] which makes it difficult to incorporate with short hospital stays. Moreover, current research does not support improvements in cognition and behavior development among moderate to late preterm infants [29].

Most intervention programs focus on educating parents in their preterm infant's behavior and needs whereas few programs aim to support the preterm infant simultaneously [24]. Intervention programs aiming to support relationships benefit by having a bidirectional focus, targeting both the preterm infant and the parents [30]. Few existing intervention programs for supporting parent-infant interaction are inclusive of both parents [24]. Therefore, psychosocial support along with engagement of both parents in the care has been suggested [31,32].

Our idea was to develop a feasible, tailored intervention program that could be incorporated with short hospital stays, a program for supporting parent-infant interactions starting at the neonatal intensive care unit for this large group of preterm infants and their parents. We developed the intervention program with the focus on sensitizing parents to the needs of the preterm infant and supporting parents' interactions with their infants in a responsive way to enhance preterm infant wellbeing and development. At the same time the preterm infant was encouraged to express needs and thereby strengthen parental abilities. By introducing the intervention in the neonatal intensive care unit and continuing after discharge we bridge the gap between the hospital stay and the home. Our focus was on supporting the moderate to late preterm infant as well as the parents simultaneously, as they are all part of the interactional pattern in the family. The aim of this study was to describe the rationale, development, framework and practical provision of a new early collaborative intervention program.

\section{Methods}

The study project is registered in an international clinical trial register, ClinicalTrials.gov NCT02034617.

\subsection{Design}

This study has a descriptive design. The rationale, development, framework and practical provision of the EArly Collaborative Intervention (EACI) program are described using the Template for Intervention Description and Replication (TIDieR) [33] as a categorization matrix.

\subsection{Setting}

The neonatal intensive care unit where the early collaborative intervention has been developed is a 16-cot family-centered, level-three, single-room unit in Sweden.

The unit has an ongoing ambition to educate staff in evidence-based methods. One focus has been on certifying staff in the Newborn Individualized Developmental Care 
and Assessment Program (NIDCAP), based upon Heidelise Als' synactive theory [34], an extension of the NBAS [3]. Assistant nurses, registered nurses and neonatologists have been trained and certified. As they have a certification in assessing newborn infant behavior and knowledge in how to support parents in caring for their preterm infant in a responsive way, seven of them also performed the early collaborative intervention program. The seven nurses and assistant nurses are called EACI-providers. Their competencies have also been used to develop the intervention program.

\subsection{Standard Care at the Unit}

Standard care for moderate to late preterm infants is provided by parents with support from registered nurses and assistant nurses. Parents are expected to stay at the unit day and night, together with their preterm infant and skin-to-skin care is routinely practiced. At the unit the parents have a kitchen for preparing meals with space to invite healthy relatives and friends, and siblings are welcome to stay with their family as well. As soon as the preterm infant is cardiorespiratory stable and is able to feed small amounts, the family is discharged from hospital to homecare, which includes checkups from a nurse twice a week. When the preterm infant can feed without the support of a feeding tube, the family is discharged from homecare.

\subsection{Participants}

Participants are families with moderate to late preterm infants at the neonatal intensive care unit. They usually have a rather short hospital stay and are in need of an early, flexible support incorporated during care. The parents are the primary caregivers during the hospital stay, and care is therefore dependent on the experiences and sensitivity of the parents.

\subsection{Procedure}

Families with moderate to late preterm infants are within the first three days after the preterm infant's birth asked to be involved in the EACI program. Families are given information and those who consent are included. The coordinator nurse assigns an EACIprovider to provide the EACI according to the planned schedule.

\subsection{Ethical Considerations}

For the evaluation of the early collaborative intervention program, ethical approval was obtained from the Regional Research Ethics Committee, registration number 2013/36731. Parents were asked for permission and provided written informed consent for publication of the written summary with photos, the Supplemental File S1.

\section{Results}

The theoretical framework of the early collaborative intervention program is based on the attachment theory and Mary Ainsworth's early work on parent sensitivity [2,5]. A secure attachment is facilitated by high-quality parent-infant interaction [1,2]. To develop a well-functioning, parent-infant interaction the parent needs to be sensitive towards the infant's cues and read, interpret and respond to the cues prompt and accurately. Thus, parental responsiveness is one of the core concepts of the early collaborative intervention. Additionally, the intervention is influenced by the NBAS, in explaining the infant's response to the environment and the infant's interactive behavior [3], making the infant cues and behavior visible for the parent and thereby possible to respond to. The start of the EACI program happens early after the preterm infant's birth as an early start have shown to improve parent-infant relations [24].

The early collaborative intervention program is described according to the TIDieR checklist [33] below and in Table 1. 
Table 1. TIDieR items and description of the EACI.

\begin{tabular}{|c|c|c|}
\hline TIDieR Item & Content & Key Components of the EACI \\
\hline 1 & The name & The EArly Collaborative Intervention, the EACI program \\
\hline \multirow[t]{2}{*}{2} & (a) The rationale & $\begin{array}{l}\text { To support parents and preterm infants in a tailored individualized way } \\
\text { To support parent-infant interaction in the NICU } \\
\text { To establish equality among every parent and preterm infant } \\
\text { To improve a well-suited care and thus achieve the best possible } \\
\text { infant development } \\
\text { To facilitate early discharge for preterm infants and parents }\end{array}$ \\
\hline & (b) The development & $\begin{array}{l}\text { In a Swedish NICUD } \\
\text { eveloped and standardized by a core-group }\end{array}$ \\
\hline 3 & Informational materials & Primarily hands-on guidance with a short summary report \\
\hline 4 & The procedure & $\begin{array}{l}\text { Parent support in awareness of the infant's attempt to interact } \\
\text { Giving words to the cues of the preterm infant } \\
\text { Instant feedback and guidance during active parental involvement }\end{array}$ \\
\hline 5 & The providers & NIDCAP-educated and certified \\
\hline 6 & The delivery & $\begin{array}{l}\text { Both parents included } \\
\text { Collaboration between infant, parents and staff } \\
\text { One family at a time } \\
\text { One provider at a time } \\
\text { A guided practice during natural care-taking procedures }\end{array}$ \\
\hline 7 & Where the intervention occurred & $\begin{array}{l}\text { In a natural setting } \\
\text { In the hospital and in the family's home when discharged }\end{array}$ \\
\hline 8 & When and how much & $\begin{array}{l}\text { Three times: within } 72 \mathrm{~h} \text { after birth, within } 48 \mathrm{~h} \text { before discharge and } \\
\text { when full-term } \\
\text { When the family decides it is feasible }\end{array}$ \\
\hline 9 & Tailoring of the intervention program & $\begin{array}{l}\text { Additional EACI-sessions if needed } \\
\text { The family's needs are the guiding principle } \\
\text { Adaptions in terms of length for each EACI-session }\end{array}$ \\
\hline 10 & Modifications & Flexibility is incorporated due to the families' individual needs \\
\hline 11 & $\begin{array}{l}\text { Intervention program adherence or } \\
\text { fidelity assessment }\end{array}$ & $\begin{array}{l}\text { Considerations on adherence of the provision of the EACI as well as the } \\
\text { written summary }\end{array}$ \\
\hline 12 & $\begin{array}{l}\text { To the extent the intervention } \\
\text { program is delivered }\end{array}$ & $\begin{array}{l}\text { Deviations may occur if the family is discharged or transferred to } \\
\text { another hospital }\end{array}$ \\
\hline
\end{tabular}

EACI = EArly Collaborative Intervention, NICU = Neonatal Intensive Care Unit, NIDCAP = Neonatal Individualized Developmental Care and Assessment Program, TIDieR = Template for Intervention Description and Replication.

\subsection{Item 1 the Name of the Intervention}

The name is the Early Collaborative Intervention (EACI) program, early, as it starts within the first days of the moderate to late preterm infant's life, collaborative, as both parents and the preterm infant are included in the guiding. The collaboration is defined as an integrated effort of the stakeholders to achieve a shared goal. Communication as well as interaction between the parents, the preterm infant and the providing staff is dependent on the feedback provided from one another. All participants during an EACI contribute to the interaction but focus is on the interaction between the parents and their preterm infant.

\subsection{Item 2 the Rationale and Development}

The rationale for developing the EACI program was experiences that individualized support provided after a NIDCAP observation were only provided for extremely preterm infants, omitting moderate and late preterm infants. There were also experiences of difficulties to communicate the infant's cues and needs to the parents when not being able to talk to them during the observation, since this is not part of a NIDCAP observation. Furthermore, a hands-on guiding for parents of moderate to late preterm infants was 
thought to be a more appropriate approach as this group of preterm infants has reached a more robust development stage than the extremely and very preterm infants. Hence, the EACI was developed to support parent-infant interaction and establish equality among infants and parents using tailored support. Furthermore, to make parents and staff aware of moderate to late preterm infants' variety of communication behavior, in order to improve a well-suited care thus achieving optimal infant development. Additionally, as the hospital stay becomes shorter, facilitating early discharge as preterm infants are cared for by their parents at home supported by neonatal homecare.

The EACI program was designed and developed in a Swedish neonatal intensive care unit, by a core-group consisting of staff certified in the Newborn Individualized Developmental and Assessment Program, a nurse co-director, a physician, a psychologist and researchers in developmental psychology and neonatal nursing. The core-group had earlier been involved in research on early interventions and had clinical and theoretical knowledge. To standardize performance of intervention regarding target group, starting point and intervals of the intervention, discussions were performed within the core-group until consensus was reached. The EACI-providers were assured working hours to deliver EACI-sessions in the hospital as well as in the families' homes.

\subsection{Item 3 Informational Materials}

Focus during the provision of the EACI is on verbal communication. Still, some notes are taken by the EACI-provider, to later help the parents recall the session. The communication is based on the infants ' behavior and the parents' interaction with their preterm infant and results in a short, written summary. The summary is usually one or two A 4 pages, including photos to further highlight different reactions or cues of the infant. Photos are especially important for parents with difficulties reading Swedish and parents who for any reasons have difficulties benefiting from a written document. The summary is included to the infants' medical charts and a copy is given to the parents. In the summary the infant's behavior and communicative activities is briefly described along with suggestions for the parents on how they can care for and interact with their preterm infant. An example of the short summary is provided in the Supplemental File S1.

\subsection{Item 4 the Procedure of the $E A$}

One important goal is to support parents in their awareness of their preterm infant's efforts to interact with the parents. By doing so the EACI-provider guides the parents to see, interpret and respond to the infant's cues. Based on the infant's alertness, the parents can for example be asked to come closer to the infant's face facilitating opportunity for communication in a way suitable for both the infant and parents. The time of infant alertness may be short and the parents will have to adjust their communication not to overload the preterm infant immature neurological system.

Another goal during the EACI is to guide the parent-infant dyad by giving words to the infant's behaviors and cues. The EACI-providers specifically guide the parents to acknowledge cues of distress, stability, breathing irregularities, grimaces, movements, tone, state-regulation, social and self-balancing capacity. Based on what the provider and the parents observe, the provider can give recommendations on how the environment around the premature infant and the care of the infant can be improved. For example, if the infant stretches and tries to brace his or her feet against something, the provider may ask the parents questions based on the behavior of the infant. Such as: What do you think your infant's stretching behavior means? or How can you support your infant when she or he is stretching like this? The parents are therefore made aware of the infant's efforts to self-regulate by attempting to support his or her feet. If not noticed by the parents, the EACI-provider shows and describes how the parents can assist the behavior by supporting the infant's feet with, for example their hands. Questions are not only to help the parents focus on the needs of the preterm infant but also to help the parents see the cues by themselves, and thereby feel more confident and secure in taking care of their preterm 
infant. The infant's response to the care is immediately communicated by words and gestures by the provider to the parents, and together the provider and parents give words to the behavior of the infant. The focus is also on encouraging parents to acknowledge the infant's current developmental stage and to recognize and be prepared for the next developmental steps.

\subsection{Item 5 the Providers}

To increase reliability, the EACI was delivered only by staff certified in the Newborn Individualized Developmental and Assessment Program. To gain a certification, education together with systematic behavioral observations supervised by a trainer is mandatory. Focus is on learning the preterm infant's behavioral language and the establishment of a relationship-based care, instead of a task-oriented care. In line with this, the training raises the importance of emotional availability towards the infant as well as the parents [35]. The emotional availability construct is intended to capture the degree to which both the parent and the infant are accessible and able to respond appropriately to the other's emotional signals [36]. To ensure competence, the EACI providers had been NIDCAP-certified for 3 to 12 years, (mean 6.8 years) and had between 15 to 40 years of experience working in the neonatal intensive care unit.

\subsection{Item 6 the Delivery}

The EACI is delivered with both parents present at a time chosen by them. If for any reason only one parent is present, the EACI-provider describes the outcome of the EACI to the other parent as soon as convenient for the family. The parents ' perceptions, descriptions and emotions regarding their infant are valuable contributions to the understanding of the family situation, and parents are encouraged to share their views of their preterm infant. It is the needs of the infant and the parents as well as paying respect to their situation, knowledge and previous experiences that are the guiding principles. The intervention is delivered for one family at a time, by one provider at a time. A coordinator nurse at the unit organizes for a provider to be able to provide the family with an EACI within the timeframe. The seven EACI-providers were providing the intervention at the hospital as well as in the families' homes. Different EACI-providers may provide the same family with the interventions at different occasions. The choice of EACI-provider is dependent on who is scheduled for work. The EACI-sessions can take place during breastfeeding, a diaper change, a bath or other routine care-taking procedures.

\subsection{Item 7 Where the EACI Was Delivered}

The first and second EACI-sessions are delivered at the hospital and the third in the family's home. Each EACI-session is delivered in a natural setting in the room where the family stays, whether it is an intensive care room or a family-room at the unit or in the family's home.

\subsection{Item 8 When and How Much}

At least three EACI-sessions are delivered, at a time appropriate to both the parents and the preterm infant. However, the first EACI should be delivered within $72 \mathrm{~h}$ after birth and the second within $48 \mathrm{~h}$ before the family leaves the hospital. The EACI-sessions in the hospital requires a minimum of preparation once the EACI-provider is familiar with the intervention. As there is a need for the parents to be able to recognize their preterm infant's development and customize their care both in hospital and after discharge, the third EACI-session is delivered after discharge, when the premature infant is full-term, Figure 1. 


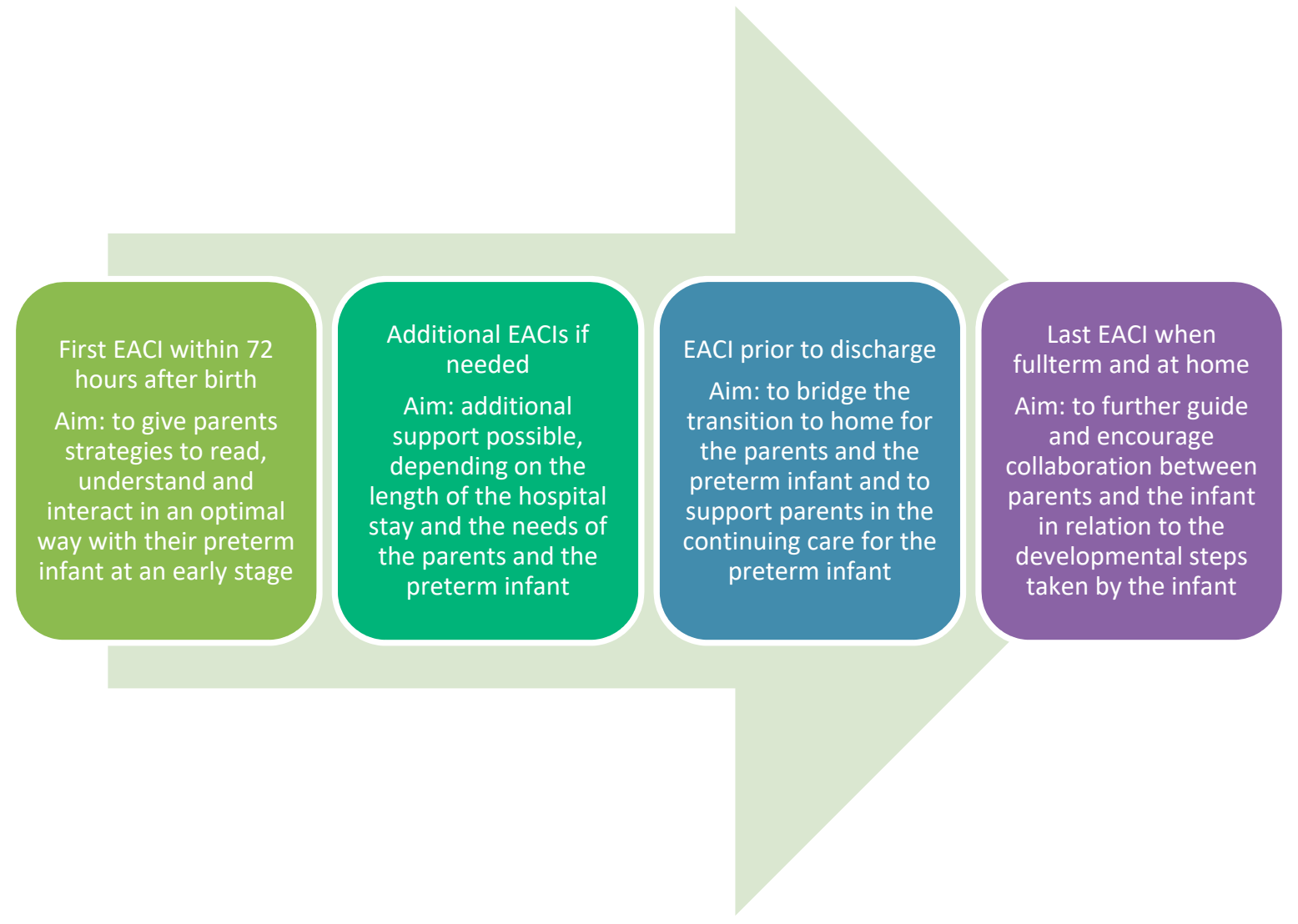

Figure 1. Flowchart of the EACIs and a description of the content during each session.

\subsection{Item 9 Tailoring of the EACI}

Depending on the feedback from the preterm infant and the parents, the provider may need to adapt the intervention. This adaption may consist of additional EACI-sessions, a necessity due to the family's situation and length of hospital stay. The length of the EACI may differ. Usually the delivery of one EACI-session takes about one to two hours, since it is the family's needs that determine how much time the providers spend with each family. The time spent delivering each EACI-session also depends on the alertness of the preterm infant, the parents' skills and whether the EACI-provider and the parents acquire the opportunity to capture the preterm infant's needs and competences.

\subsection{Item 10 Modifications of the EACI}

There is a flexibility incorporated in the EACI, since the interaction between the EACIprovider and the parents and the feedback from the parents are taken into consideration when delivering the EACI. Depending on the feedback from parents and the infant, the provider may need to modify the support to suit their current individual needs.

\subsection{Item 11 Intervention Adherences of the EACIs}

At the start of delivering the intervention program recurrent discussions within the core group were performed to bring consensus on the provision as well as the written summary. When the EACI-providers became used to working with the EACI, discussions and support were ongoing within the provider group.

\subsection{Item 12 to the Extent EACI Was Delivered as Planned}

The aim was to deliver every family with at least three EACI-sessions. For the time being, 196 EACI-sessions have been delivered for 70 families. Out of these families 45 have received three sessions and seven families have received four or five sessions due to an 
extensive hospital stay or a need for the extra guidance (as described in item 9). Fourteen families have had two sessions. Remaining four families have received less sessions. Reasons for not having all the three EACI-sessions could be a very short hospital-stay for the family, lack of qualified staff or an unexpected transfer to another hospital due to lack of intensive care beds.

\section{Discussion}

This study describes a new early collaborative intervention program. It is developed to be used in the neonatal intensive care unit to support parents and their moderate to late preterm infants, as there is a lack of an intervention program designed for this group. Fundamental to this program is that a sensitive and responsive parental behavior is a prerequisite for a well-functioning parent-infant interaction which in turn, facilitates a secure attachment and optimized cognitive development for the infant.

The EACI program strives to empower and support parents to interact with their infant and to strengthen emotional mutuality. The guiding is based on the knowledge of Ainsworths' work on how parents need to act sensitive towards infant's cues in order to establish a well-functioning interaction [2]. Early interventions starting in the neonatal intensive care unit, have previously shown to improve parent-infant relations [24]. However, several interventions are more extensive than the EACI program [24]. For example, the Mother Infant Transaction Program improves preterm parent-infant interaction [27] but the extensiveness of the program makes it difficult to incorporate with short hospital stays, as in our setting. Since there are time and economic constraint in public healthcare, it is important to find a feasible but still effective intervention program. The EACI program is delivered without preparation and the written summary after the session is short but still, an important addition to the dialogue. The written summary serves as an objective report that the parents can bring home as a complementary support after a short hospital stay. The objective was to provide every family with three EACI-sessions. One reason for delivering a reduced number of sessions is a lack of intensive care beds on the unit which has been described as a limiting factor in the neonatal context [37].

The EACI is provided through an individual, mutual discussion in a dialogue manner, focusing on both parents and infant simultaneously. This builds upon previous research showing that intervention programs targeting the relationship between preterm infants and their parents should be individualized $[31,38]$ and target both the preterm infant and the parents [30]. Preterm birth impacts the expected new role as a parent [39]. This is not just for the mothers; the interactive paternal-preterm infant pattern has also shown to affect preterm infant development [40]. A father active in caretaking has a positive effect on maternal-preterm infant interactive behavior [41]. It has been suggested that paternal negative feelings of the mother-preterm infant interactive behavior in turn have a negative effect on the mother's interactive behavior [42], while including fathers in interventions in the neonatal intensive care unit can facilitate the spouse relationship [43], pointing at the importance of supporting both parents as they are part of the interactive pattern in the family.

Support has also been suggested to be effective when made into a collaboration between parents and staff [44], based on the preterm infant's cues [25,45]. EACI offers a way to support parent-infant relations as the provider explains the preterm infant's subtle cues in order to help parents feel secure in caring for their infant. Preterm infant subtle cues are often difficult to notice and respond to and may be misunderstood as an infant averting behavior. Understanding the cues will also help parents enjoy their preterm infant and thereby strengthening the relationship further. Mothers have previously described how a well-functioning interaction with their late preterm infants improved their feelings of motherhood [46].

Parents in the neonatal context have previously highlighted how well-functioning communication with staff is of great importance in managing the stressful situation of being a parent to a preterm infant [47], and how the communication can guide them in 
understanding their preterm infant's relational needs [48]. During the EACI, the parents' perceptions, descriptions and emotions regarding their infant are valuable contributions to the understanding of the family situation. Parents are encouraged to share their view about their preterm infant and the communication between the parents and the EACI-provider is an important part of the collaboration. This is in accordance with the Mother Infant Transaction Program [28]. However, where the Mother Infant Transaction Program uses the reflective dialogue to focus solely on the parent in caring for the infant, the EACI have a bidirectional aim, focusing on both the parent and the preterm infant.

It is important to pay attention to all preterm infants in the neonatal intensive care unit, regardless of gestational age, as delays in physical and cognitive developmental outcomes are evident even for moderate and late preterm infants [12,49]. It is vitally important to involve parents in the care, as this is recommended for optimal development $[35,50]$. Moderate and late preterm infants often have a shorter hospital stay, compared to very and extremely preterm infants. This puts a large responsibility on the parents in being able to recognize and respond to their preterm infant in a suitable way after discharge. The EACI program may offer a way of supporting parents and preterm infants. Moreover, since moderate to late preterm infants constitute a large group in the neonatal care, the EACI program offers great opportunities to improve development and parental confidence in many families otherwise left without specific support. The EACI program brings equality among preterm infants and their parents in an intensive care context where otherwise much focus is on extremely preterm infants [51].

This study gives no evidence of if the EACI program can increase parent-infant interaction. Further studies are needed to objectively evaluate the program from a staff and parent perspective as well as to report outcomes from an ongoing randomized controlled trial. In the study project, follow-ups are performed at one, four and twelve months and at four years since more longitudinal follow-ups are required to study long-term effects [52]. At one and four months parent-infant interaction is videotaped and will later be analyzed using two different instruments, the Ainsworth's Maternal Sensitivity Scales including four subscales [53] and the Emotional Availability Scales, including six subscales [54]. Outcomes regarding, breastfeeding, parental depressive and anxiety symptoms, parental experiences of infant socio-emotional behavior and salivary cortisol will also be evaluated. Furthermore evaluation of factors known to be affected from parent-infant interaction and intervention programs [44] will be made. Infant cognition, language, motor skills and behavior will be assessed at twelve months with The Bayley Scales of Infant and Toddler DevelopmentIII [55]. At four years of age the child will be assessed with Wechsler Preschool and Primary Scale of Intelligence-IV [56] to tap cognition, language, visual-spatial skills and memory. Parents perceived stress, perceived parental functions will be evaluated by questionnaires.

\section{Strengths and Limitations}

This new early intervention program fills a gap, as it focuses on moderate to late preterm infants that usually have a rather short hospital stay. It is developed in collaboration with staff in the neonatal intensive care unit, and provides immediate, individualized, reflexive support to both parents and preterm infants simultaneously. The intervention is grounded by an interdisciplinary group of clinicians and researchers in collaboration with staff from the neonatal intensive care unit.

Another strength of this paper is the thorough description of the EACI program according to the TIDieR [33].

However, one limitation is that at this stage only a small group of seven nurses with a certification in the NIDCAP are performing the EACI-sessions. The purpose for this was to ensure quality of the delivered program during the randomized controlled trial. Further studies will evaluate if the EACI program can be provided by staff without the certification, with maintained quality. 


\section{Conclusions}

This study describes a new early collaborative intervention program for moderate to late preterm infants and their parents, founded in the attachment theory. The objective is to improve parent-infant interaction which in turn will facilitate attachment and cognitive development of the infant.

Supplementary Materials: The following are available online at https://www.mdpi.com/article/10 $.3390 /$ ijerph18126656/s1, Supplemental File S1, EACI of a preterm infant.

Author Contributions: Conceptualization, methodology, validation, formal analysis and resources, C.S.H., U.B.T., and E.M. Writing-original draft preparation, C.S.H. Writing-review and editing and visualization, C.S.H., U.B.T. and E.M. Supervision, U.B.T. and E.M. Project administration and funding acquisition, C.S.H., U.B.T. and E.M. All authors have read and agreed to the published version of the manuscript.

Funding: This work was supported by Stiftelsen Samariten, Lilla Barnets fond and Region Östergötland, [LIO-922331]. The funders had no role in study design, data collection and analysis, decision to publish or preparation of the manuscript.

Institutional Review Board Statement: The development and practical provision of the intervention was conducted according to the guidelines of the Declaration of Helsinki. For the evaluation of the early collaborative intervention program, ethical approval was obtained from the Regional Research Ethics Committee, registration number 2013/367-31.

Informed Consent Statement: Parents provided written informed consent for publication of the written summary with photos.

Data Availability Statement: Not applicable.

Acknowledgments: We are grateful to the provider group for their valuable contribution to this study by delivering the intervention program to the preterm families. Furthermore, we are grateful to Gemma Safikhani Kashkooli for language review.

Conflicts of Interest: The authors declare no conflict of interest. The funders had no role in the design of the study, in the writing of the manuscript or in the decision to publish the results.

\section{References}

1. Bowlby, J. Attachment and Loss; Basic Books: New York, NY, USA, 1969.

2. Ainsworth, M.D.S. Infant-Mother Attachment. Am. Psychol. 1979, 34, 932-937. [CrossRef]

3. Brazelton, B.; Als, H.; Tronick, E.; Lester, B. The Brazelton Neonatal Behavioral Assessment Scale (BNBAS). J. Abnorm. Child Psychol. 1977, 5, 215-229. [CrossRef]

4. Broberg, A.G. A review of interventions in the parent-child relationship informed by attachment theory. Acta Paediatr. Int. J. Paediatr. 2000, 89, 37-42. [CrossRef]

5. Cassidy, J.; Jones, J.D.; Shaver, P.R. Contributions of attachment theory and research: A framework for future research, translation, and policy. Dev. Psychopathol. 2013, 25 Pt 2, 1415-1434. [CrossRef]

6. Deans, C.L. Maternal sensitivity, its relationship with child outcomes, and interventions that address it: A systematic literature review. Early Child Dev. Care 2020, 190, 252-275. [CrossRef]

7. Pisoni, C.; Spairani, S.; Fauci, F.; Ariaudo, G.; Tzialla, C.; Tinelli, C.; Politi, P.; Balottin, U.; Stronati, M.; Orcesi, S. Effect of maternal psychopathology on neurodevelopmental outcome and quality of the dyadic relationship in preterm infants: An explorative study. J. Matern.-Fetal Neonatal Med. 2020, 33, 103-112. [CrossRef]

8. Feldman, R.; Eidelman, A.I. Neonatal state organization, neuromaturation, mother-infant interaction, and cognitive development in small-for-gestational-age premature infants. Pediatrics 2006, 118, e869-e878. [CrossRef] [PubMed]

9. Baum, N.; Weidberg, Z.; Osher, Y.; Kohelet, D. No Longer Pregnant, Not Yet a Mother: Giving Birth Prematurely to a Very-LowBirth-Weight Baby. Qual. Health Res. 2012, 22, 595-606. [CrossRef]

10. Flacking, R.; Lehtonen, L.; Thomson, G.; Axelin, A.; Ahlqvist, S.; Moran, V.H.; Ewald, U.; Dykes, F.; The SCENE Group. Closeness and separation in neonatal intensive care. Acta Paediatr. 2012, 101, 1032-1037. [CrossRef] [PubMed]

11. Jiang, S.Y.; Warre, R.; Qiu, X.M.; O’Brien, K.; Lee, S.K. Parents as practitioners in preterm care. Early Hum. Dev. 2014, 90, 781-785. [CrossRef] [PubMed]

12. Cheong, J.L.; Doyle, L.; Burnett, A.C.; Lee, K.J.; Walsh, J.M.; Potter, C.R.; Treyvaud, K.; Thompson, D.K.; Olsen, J.E.; Anderson, P.J.; et al. Association Between Moderate and Late Preterm Birth and Neurodevelopment and Social-Emotional Development at Age 2 Years. JAMA Pediatrics 2017, 171, e164805. [CrossRef] 
13. Yun Sung, N.; Ju Sun, H.; Jung Hye, B.; Eun Hee, L. Neurodevelopmental Outcomes of Moderate-to-Late Preterm Infants. Neonatal Med. 2020, 27, 159-166. [CrossRef]

14. Flores, C.T.; Gerstein, A.; Phibbs, C.S.; Sanders, L.M. Short-term and long-term educational outcomes of infants born moderatwly and late preterm. J. Pediatrics 2020, 232, 31-37. [CrossRef]

15. Thunqvist, P.; Gustafsson, P.M.; Schultz, E.S.; Bellander, T.; Berggren-Broström, E.; Norman, M.; Wickman, M.; Melén, E.; Hallberg, J. Lung Function at 8 and 16 Years After Moderate-to-Late Preterm Birth: A Prospective Cohort Study. Pediatrics 2016, 137. [CrossRef]

16. WHO. Preterm Birth 2018. Available online: http://www.who.int/en/news-room/fact-sheets/detail/preterm-birth (accessed on 30 March 2021).

17. NVSS. Births U.S. Department of Health and Human Services: U.S. Department of Health and Human Services, Centers for Disease Control and Prevention, National Center for Health Statistics, National Vital Statistics System. 2019. Available online: https:/ / www.cdc.gov/nchs/data/nvsr/nvsr68/nvsr68_13-508.pdf (accessed on 7 January 2021).

18. Socialstyrelsen. Statistikdatabas för Graviditeter, Förlossningar och Nyfödda. 2020. Available online: https://sdb.socialstyrelsen. se/if_mfr_004/resultat.aspx (accessed on 21 January 2021).

19. Yamamoto, S.; Premji, S. The role of body, mind, and environment in preterm birth: Mind the gap. J. Midwifery Women's Health 2017, 62, 696-705. [CrossRef]

20. Karnati, S.; Kollikonda, S.; Abu-Shaweesh, J. Late preterm infants-Changing trends and continuing challenges. Int. J. Pediatrics Adolesc. Med. 2020, 7, 38-46. [CrossRef]

21. Van Hus, J.W.P.; Jeukens-Visser, M.; Koldewijn, K.; Holman, R.; Kok, J.H.; Nollet, F.; Van Wassenaer-Leemhuis, A.G. Early intervention leads to long-term developmental improvements in very preterm infants, especially infants with bronchopulmonary dysplasia. Acta Paediatr. 2016, 105, 773-781. [CrossRef]

22. Jarjour, I.T. Neurodevelopmental Outcome After Extreme Prematurity: A Review of the Literature. Pediatric Neurol. 2015, 52, 143-152. [CrossRef] [PubMed]

23. Nordhov, M.S.; Rønning, J.A.; Dahl, L.B.; Ulvund, S.E.; Tunby, J.; Kaaresen, P.I. Early intervention improves cognitive outcomes for preterm infants: Randomized controlled trial. Pediatrics 2010, 126, e1088-e1094. [CrossRef]

24. Shuby, P.; Muhammad, C.; Pei-Ching, T.; Lesley, K.; Jogesh, K. Effectiveness of early intervention programs for parents of preterm infants: A meta-review of systematic reviews. BMC Pediatrics 2018, 18, 223. [CrossRef]

25. Evans, T.; Whittingham, K.; Sanders, M.; Colditz, P.; Boyd, R.N. Are parenting interventions effective in improving the relationship between mothers and their preterm infants? Infant Behav. Dev. 2014, 37, 131-154. [CrossRef]

26. Barlow, J.; Herath, N.I.; Bartram Torrance, C.; Bennett, C.; Wei, Y. The Neonatal Behavioral Assessment Scale (NBAS) and Newborn Behavioral Observations (NBO) system for supporting caregivers and improving outcomes in caregivers and their infants. Cochrane Database Syst. Rev. 2018, 3. [CrossRef]

27. Ravn, I.H.; Smith, L.; Lindemann, R.; Smeby, N.A.; Kyno, N.M.; Bunch, E.H.; Sandvik, L. Effect of early intervention on social interaction between mothers and preterm infants at 12 months of age: A randomized controlled trial. Infant Behav. Dev. 2011, 34, 215-225. [CrossRef] [PubMed]

28. Rauh, V.A.; Nurcombe, B.; Achenbach, T.; Howell, C. The Mother-Infant Transaction Program: The Content and Implications of an Intervention for the Mothers of Low-Birthweight Infants. Clin. Perinatol. 1990, 17, 31-45. [CrossRef]

29. Kynø, N.M.; Ravn, I.H.; Lindemann, R.; Fagerland, M.W.; Smeby, N.A.; Torgersen, A.M. Effect of an early intervention programme on development of moderate and late preterm infants at 36 months: A randomized controlled study. Infant Behav. Dev. 2012, 35, 916-926. [CrossRef] [PubMed]

30. Spittle, A.; Orton, J.; Anderson, P.J.; Boyd, R.; Doyle, L.W. Early developmental intervention programmes provided post hospital discharge to prevent motor and cognitive impairment in preterm infants. Cochrane Database Syst. Rev. 2015. [CrossRef] [PubMed]

31. Treyvaud, K.; Spittle, A.; Anderson, P.J.; O'Brien, K. A multilayered approach is needed in the NICU to support parents after the preterm birth of their infant. Early Hum. Dev. 2019, 139, 104838. [CrossRef]

32. Heo, Y.J.; Oh, W.-O. The effectiveness of a parent participation improvement program for parents on partnership, attachment infant growth in a neonatal intensive care unit: A randomized controlled trial. Int. J. Nurs. Stud. 2019, 95, 19-27. [CrossRef] [PubMed]

33. Hoffmann, T.C.; Glasziou, P.P.; Boutron, I.; Milne, R.; Perera, R.; Moher, D.; Altman, D.G.; Barbour, V.; Macdonald, H.; Johnston, M.; et al. Better reporting of interventions: Template for intervention description and replication (TIDieR) checklist and guide. BMJ Clin. Res. 2014, 348, g1687. [CrossRef] [PubMed]

34. Als, H. A synactive model of neonatal behavioral organization: Framework for the assessment of neurobehavioral development in the premature infant and for support of infants and parents in the neonatal intensive care environment. Phys. Occup. Ther. Pediatrics 1986, 6, 3-53. [CrossRef]

35. Craig, J.W.; Glick, C.; Phillips, R.; Hall, S.L.; Smith, J.; Browne, J. Recommendations for involving the family in developmental care of the NICU baby. J. Perinatol. 2015, 35, 5-8. [CrossRef] [PubMed]

36. Biringen, Z.; Robinson, J. Emotional Availability in Mother-Child Interactions: A Reconceptualization for Research. Am. J. Orthopsychiatry 1991, 61, 258-271. [CrossRef] [PubMed] 
37. Mörelius, E.; Olsson, E.; Sahlén Helmer, C.; Thernström Blomqvist, Y.; Angelhoff, C. External barriers for including parents of preterm infants in a randomised clinical trial in the neonatal intensive care unit in Sweden: A descriptive study. BMJ Open 2020, 10, e040991. [CrossRef]

38. Suttora, C.; Spinelli, M.; Aureli, T.; Fasolo, M.; Lionetti, F.; Picciolini, O.; Ravasi, M.; Salerni, N. Mind-Mindedness and Parenting Stress: A Cross-Sectional Study in a Cohort of Mothers of 3-Month-Old Full-Term and Preterm Infants. Int. J. Environ. Res. Public Health 2020, 17, 7735. [CrossRef] [PubMed]

39. Ionio, C.; Mascheroni, E.; Colombo, C.; Castoldi, F.; Lista, G. Stress and feelings in mothers and fathers in NICU: Identifying risk factors for early interventions. Prim. Health Care Res. Dev. 2019, 20, e81. [CrossRef] [PubMed]

40. McMahon, G.E.; Spencer-Smith, M.M.; Pace, C.C.; Spittle, A.J.; Stedall, P.; Richardson, K.; Cheong, J.L.; Doyle, L.W.; Anderson, P.J.; Treyvaud, K. Influence of Fathers' Early Parenting on the Development of Children Born Very Preterm and Full Term. J. Pediatrics 2019, 205, 195-201. [CrossRef]

41. Holditch-Davis, D.; Schwartz, T.; Black, B.; Scher, M. Correlates of mother-premature infant interactions. Res. Nurs. Health 2007, 30, 333-346. [CrossRef] [PubMed]

42. Ionio, C.; Lista, G.; Mascheroni, E.; Olivari, M.G.; Confalonieri, E.; Mastrangelo, M.; Brazzoduro, V.; Balestriero, M.A.; Banfi, A.; Bonanomi, A.; et al. Premature birth: Complexities and difficulties in building the mother-child relationship. J. Reprod. Infant Psychol. 2017, 35, 509-523. [CrossRef]

43. Mörelius, E.; Örtenstrand, A.; Theodorsson, E.; Frostell, A. A randomised trial of continuous skin-to-skin contact after preterm birth and the effects on salivary cortisol, parental stress, depression, and breastfeeding. Early Hum. Dev. 2015, 91, 63-70. [CrossRef]

44. Griffiths, N.; Spence, K.; Loughran-Fowlds, A.; Westrup, B. Individualised developmental care for babies and parents in the NICU: Evidence-based best practice guideline recommendations. Early Hum. Dev. 2019, 139, 104840. [CrossRef]

45. Lavallée, A.; De Clifford-Faugère, G.; Ballard, A.; Aita, M. Parent-Infant Interventions to Promote Parental Sensitivity During NICU Hospitalization: Systematic Review and Meta-Analysis. J. Early Interv. 2021, 105381512199192. [CrossRef]

46. Premji, S.S.; Pana, G.; Currie, G.; Dosani, A.; Reilly, S.; Young, M.; Hall, M.; Williamson, T.; Lodha, A.K. Mother's level of confidence in caring for her late preterm infant: A mixed methods study. J. Clin. Nurs. 2018, 27, E1120-E1133. [CrossRef]

47. Wigert, H.; Blom, M.D.; Bry, K. Parents' experiences of communication with neonatal intensive-care unit staff: An interview study. BMC Pediatrics 2014, 14, 304. [CrossRef] [PubMed]

48. Guillaume, S.; Michelin, N.; Amrani, E.; Benier, B.; Durrmeyer, X.; Lescure, S.; Bony, C.; Danan, C.; Baud, O.; Jarreau, P.-H.; et al. Parents' expectations of staff in the early bonding process with their premature babies in the intensive care setting: A qualitative multicenter study with 60 parents. BMC Pediatrics 2013, 13, 18. [CrossRef] [PubMed]

49. Martínez-Nadal, S.; Bosch, L. Cognitive and Learning Outcomes in Late Preterm Infants at School Age: A Systematic Review. Int. J. Environ. Res. Public Health 2020, 18, 74. [CrossRef]

50. Ferreira, R.D.C.; Alves, C.R.L.; Guimarães, M.A.P.; De Menezes, K.K.P.; Magalhães, L.D.C. Effects of early interventions focused on the family in the development of children born preterm and/or at social risk: A meta-analysis. J. Pediatr. 2020, 96, 20-38. [CrossRef] [PubMed]

51. Manuck, T.A.; Rice, M.M.; Bailit, J.L.; Grobman, W.A.; Reddy, U.M.; Wapner, R.; Thorp, J.M.; Caritis, S.N.; Prasad, M.; Tita, A.; et al. Preterm neonatal morbidity and mortality by gestational age: A contemporary cohort. Am. J. Obstet. Gynecol. 2016, 215, 103.e1-103.e14. [CrossRef] [PubMed]

52. Amin, L.; Arina, N.; Tam, W.W.S.; Shorey, S. Enhancing first-time parents' self-efficacy: A systematic review and meta-analysis of universal parent education interventions' efficacy. Int. J. Nurs. Stud. 2018, 82, 149-162. [CrossRef] [PubMed]

53. Ainsworth, M.D.S. Ainsworth Maternal Sensitivity Scales 1969. Available online: https://pdfs.semanticscholar.org/77ba/e53ad6 d26d2fc13b02f144874cfa1ab28527.pdf (accessed on 12 May 2020).

54. Biringen, Z.; Closson, L.; Derscheid, D.; Vliegen, N.; Easterbrooks, M.A. Emotional availability (EA): Theoretical background, empirical research using the EA Scales, and clinical applications. Dev. Rev. 2014, 34, 114-167. [CrossRef]

55. Bayley, N. Bayley Scales of Infant and Toddler Development, 3rd ed.; Psychological Corporation: New York, NY, USA, 2006.

56. Wechsler, D. WPPSI-IV: Wechsler Preschool and Primary Scale of Intelligence-Fourth Edition; Pearson Education: New York, NY, USA, 2014. 